\title{
Aortic to right ventricular shunt for pulmonary atresia with intact ventricular septum and bilateral coronary ostial atresia
}

Hajime Sakurai, MD, ${ }^{\mathrm{a}}$ Takahisa Sakurai, MD, ${ }^{\mathrm{a}}$ Naoki Ohashi, MD, ${ }^{\mathrm{b}}$ and Hiroshi Nishikawa, MD, ${ }^{\mathrm{b}}$ Nagoya, Japan

From the Departments of a Cardiovascular Surgery and ${ }^{b}$ Pediatric Cardiology, Japan Community Healthcare Organization Chukyo Hospital, Nagoya, Japan.

Disclosures: Authors have nothing to disclose with regard to commercial support.

Received for publication Jan 8, 2018; revisions received Feb 20, 2018; accepted for publication March 7, 2018; available ahead of print April 5, 2018.

Address for reprints: Hajime Sakurai, MD, 1-1-10 Sanjo, Minami-ku, Nagoya 457-8510, Japan (E-mail: hsaku391@gmail.com).

J Thorac Cardiovasc Surg 2018;156:e17-20

$0022-5223 / \$ 36.00$

Copyright (C) 2018 by The American Association for Thoracic Surgery

https://doi.org/10.1016/j.jtcvs.2018.03.047

Video clip is available online.

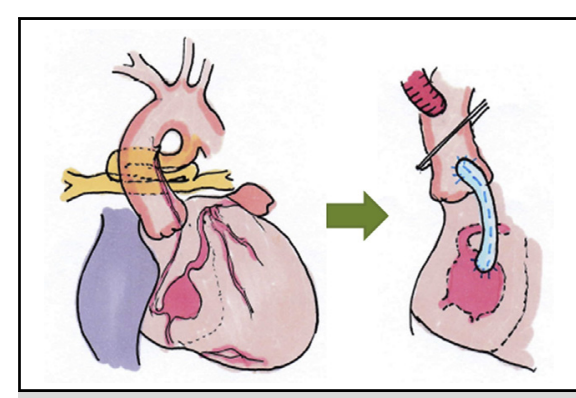

An Ao-RV shunt was reconstructed to improve coronary circulation.

\section{Central Message}

We report the first surviving case of PA/IVS and bilateral COA saved by Ao-RV shunting rather than transplantation.

See Editorial Commentary page e 21 .
Pulmonary atresia with an intact ventricular septum (PA/ IVS) and with right ventricle (RV)-dependent coronary circulation (RVDCC) is associated with worse outcomes because of perinatal ischemic events. Patients with severe PA/IVS and bilateral coronary ostial atresia (COA) have reportedly been saved by heart transplantation alone. We report a case in which the patient was saved by adding an aortic to RV (Ao-RV) shunt to the initial Blalock-Taussig shunt (BTS) without heart transplantation.

\section{CLINICAL SUMMARY}

An infant born at 39 weeks 6 days (birth weight, $3052 \mathrm{~g}$ ), was referred to our hospital with suspected univentricular heart. Postnatal echocardiography revealed PA/IVS, patent ductus arteriosus (PDA), severe hypoplastic RV, and RV coronary sinusoids. Tricuspid annulus diameter was $2.3 \mathrm{~mm}$, with no tricuspid regurgitation. Cardiac catheterization at 22 days postnatally demonstrated suprasystemic $\mathrm{RV}$ pressure of $90 \mathrm{~mm} \mathrm{Hg}$ and $\mathrm{RV}$ end-diastolic volume
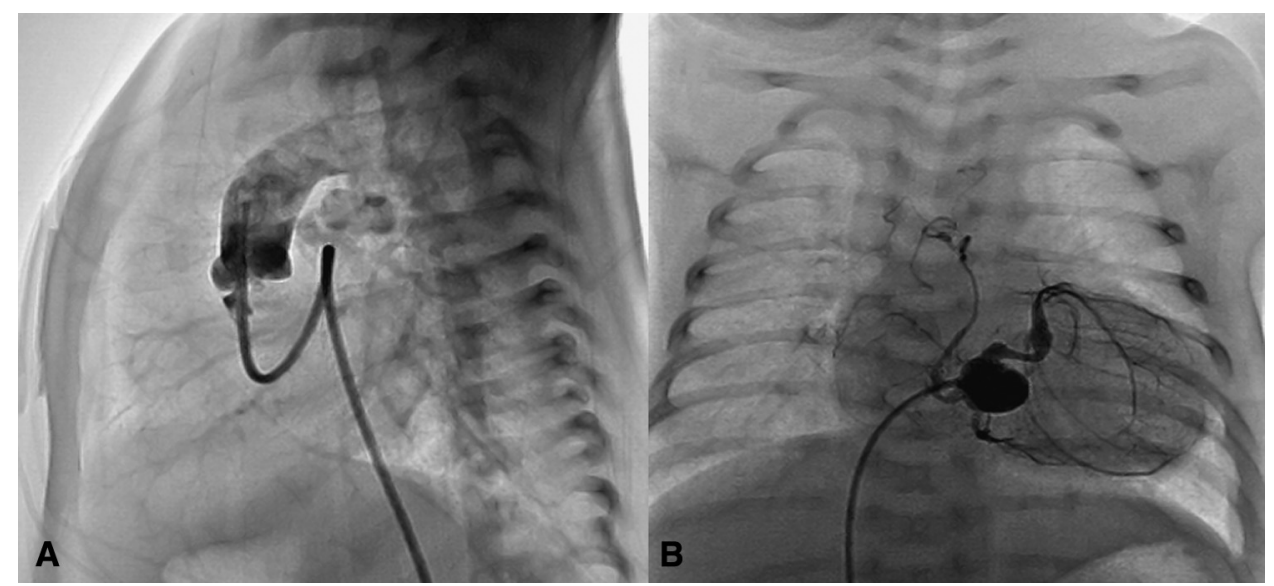

FIGURE 1. Preoperative cardiac catheter study. A, The lateral view on aortography did not show coronary arteries arising from the aorta. B, The right ventriculogram was able to identify the proximal right coronary artery, distal right coronary artery, and left coronary artery originating from the RV. 


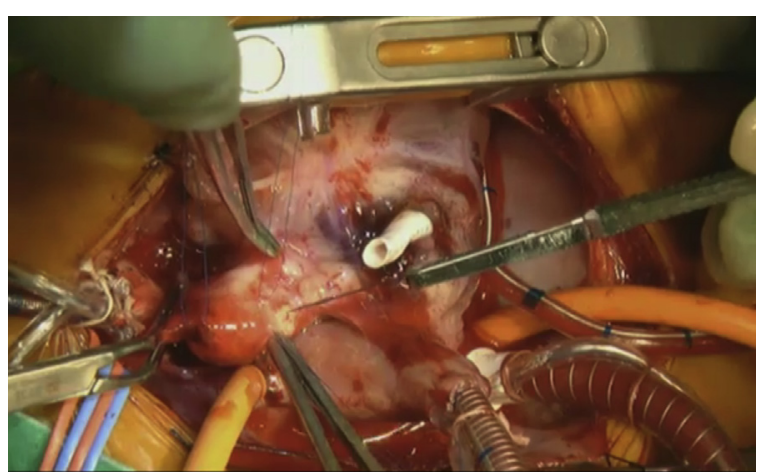

VIDEO 1. Explanation of the relevance of our case report and description of the surgical technique. Video available at: http://www.jtcvsonline.org/ article/S0022-5223(18)30826-2/fulltext.

$9 \%$ of normal. Aortography revealed no coronary arteries arising from the aorta (Figure 1, $A$ ). Instead, bilateral coronary arteries were visible on a right ventriculogram (Figure 1,B). We discussed initial treatment options of (1) transplant, (2) Ao-RV shunt + BTS, (3) BTS only, (4) medical treatment only while waiting to perform a bidirectional Glenn (BDG) shunt, or (5) end-of-life care. No survival has been reported without heart transplantation, and the likelihood of transplantation in an infant is extremely low in Japan. However, with worsening ST changes on the electrocardiogram, an enlarging left ventricular cavity, and progressive mitral regurgitation, we performed an Ao-RV shunt + BTS procedure 41 days postnatally (Video 1). After median sternotomy, cardiopulmonary bypass was carefully initiated to avoid reducing right atrial pressure. Once full flow was achieved, a cardioplegia infusion cannula (DLP 4-mm Arteriotomy Cannula; Medtronic, Inc, Minneapolis, Minn) was placed in the RV from the anterior wall with a purse-string suture. Cardiac arrest was achieved immediately after cardioplegia infusion via the RV, and the ascending aorta was crossclamped. Coronary revascularization was constructed with a $3.0-\mathrm{mm}$ polytetrafluoroethylene graft (Gore-Tex graft; WL Gore \& Associates Inc, Newark, Del) between the ascending aorta and the RV (Figure 2). The small tricuspid valve was closed using an autopericardial patch via the right atriotomy. Simultaneously, PDA closure and right BTS using a $3.5-\mathrm{mm}$ polytetrafluoroethylene graft were performed. The patient was easily weaned from cardiopulmonary bypass. He underwent secondary sternal closure on postoperative day 4 and was extubated on postoperative day 7. Left cardiac function improved postoperatively. Cardiac catheterization on postoperative day 28 showed good flow of the Ao-RV shunt and improved imaging of coronary arteries (Figure 3). BDG was performed at 4 months. Repeat surgery was

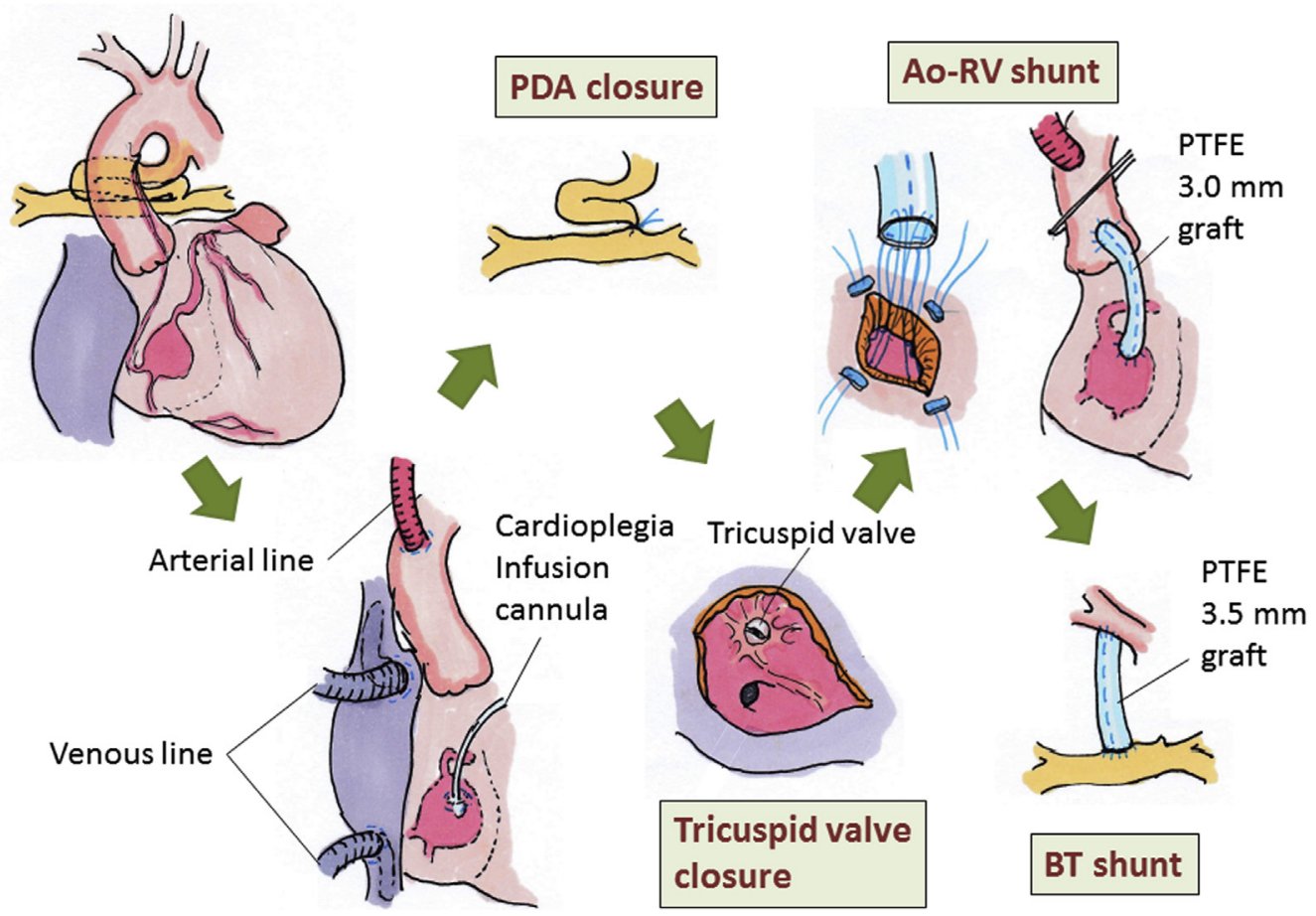

FIGURE 2. The operative procedure. Once cardiopulmonary bypass was established, the PDA was closed. Cardiac arrest was obtained by infusion of cardioplegia via the RV free wall using an arteriotomy cannula. After right atriotomy, the tricuspid valve was closed. Ao-RV shunt was made using 3.0-mm polytetrafluoroethylene graft. Finally, right BTS was performed. PDA, Patent ductus arteriosus; Ao-RV, aortic to right ventricle; PTFE, polytetrafluoroethylene; $B T$, Blalock-Taussig. 


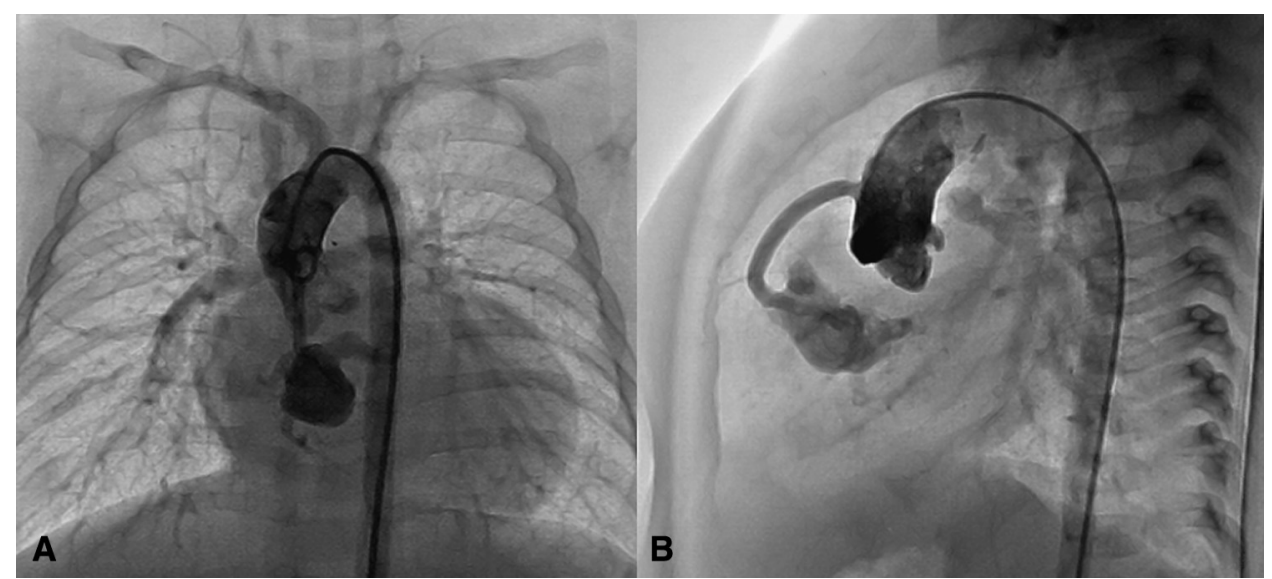

FIGURE 3. Postoperative cardiac catheter study. A, The frontal view of the aortogram showed good flow from aortic root to RV via the Ao-RV shunt. The right BTS graft and bilateral pulmonary arteries were also perfused from the innominate artery. B, The lateral view of the aortogram showed Ao-RV shunt graft and RV.

performed at 7 months of age to replace a stenotic 3.0-mm graft with a 5-mm graft. The patient was discharged well, and at 9 months of age is being followed up as an outpatient.

\section{DISCUSSION}

There is a wide morphologic spectrum of malformations within PA/IVS. When these patients have coronary abnormalities, the risk of ongoing ischemia, especially in those with RVDCC, may predispose them to higher interim and late mortality. Bilateral COA represents the most extreme form of RVDCC, with reported incidence of approximately $0.3 \%$ in patients with PA/IVS. ${ }^{1}$

Since Lenox and Briner ${ }^{2}$ described the first case of bilateral COA associated with PA/IVS in 1972, less than 20 cases have been reported. ${ }^{1,3-13}$ Among these, only a few were saved by a heart transplant in early infancy. ${ }^{10,13}$ All remaining cases died shortly after birth or early in infancy. Guleserian and colleagues ${ }^{9}$ stated that PA/IVS with aortocoronary atresia should undergo primary cardiac transplantation because of the poor prognosis.

In 1993, Freeman and colleagues ${ }^{14}$ first described Ao-RV shunting in a Fontan procedure in a 20-month-old girl with PA/IVS. However, the patient had major RV coronary connections and did not have COA. Laks and colleagues ${ }^{15}$ reported 5 successful cases of Ao-RV shunting for PA/IVS in 1995, with simultaneous BDG or Fontan procedures, but none had bilateral COA. To our knowledge, this is the first case to undergo Ao-RV shunting for PA/IVS and bilateral COA, with survival beyond early infancy without heart transplantation.

\section{CONCLUSIONS}

Although the myocardium is theoretically only perfused during systole in a totally RV-dependent coronary system, perfusion with more saturated blood mainly occurs during diastole after Ao-RV shunting. Furthermore, shunting reduces the RV systolic pressure to systemic levels while the elevated diastolic pressure improves coronary circulation. Simultaneous tricuspid orifice closure prevents less saturated blood in the right atrium from flowing into the RV and coronary arteries. We believe that an Ao-RV shunt can save these patients without a heart transplant.

\section{References}

1. Daubeney PE, Delany DJ, Anderson RH, Sandor GG, Slavik Z, Keeton BR, et al. Pulmonary atresia with intact ventricular septum: range of morphology in a population-based study. J Am Coll Cardiol. 2002;39:1670-9.

2. Lenox CC, Briner J. Absent proximal coronary arteries associated with pulmonic atresia. Am J Cardiol. 1972;30:666-9.

3. Hamazaki M. Congenital coronary arterio-ventricular fistulae, associated with absence of proximal coronary artery from aorta. Jpn Heart J. 1982;23:271-7.

4. Fyfe DA, Edwards WD, Driscoll DJ. Myocardial ischemia in patients with pulmonary atresia and intact ventricular septum. J Am Coll Cardiol. 1986;8:402-6.

5. Kasznica J, Ursell PC, Blanc WA, Gersony WM. Abnormalities of the coronary circulation in pulmonary atresia and intact ventricular septum. Am Heart J. 1987; 114:1415-20.

6. Rivera IR, Moises VA, Silva CC, Abujamra P, Andrade JL, Carvalho AC. Right ventricle-dependent coronary circulation in pulmonary atresia with intact ventricular septum. Absence of origin of the coronary arteries from the aorta. Arq Bras Cardiol. 1998;71:143-6.

7. Lajos P, Love J, Salim MA, Wang W, Cardarelli MG. Total right ventricular dependent coronary circulation in pulmonary atresia with intact ventricular septum. Ann Thorac Surg. 2004;77:1087-8.

8. Selamet SE, Hsu DT, Thaker HM, Gersony WM. Complete atresia of coronary ostia in pulmonary atresia and intact ventricular septum. Pediatr Cardiol. 2004;25:67-9.

9. Guleserian KJ, Armsby LB, Thiagarajan RR, del Nido PJ, Mayer JE. Natural history of pulmonary atresia with intact ventricular septum and right-ventricledependent coronary circulation managed by the single-ventricle approach. Ann Thorac Surg. 2006;81:2250-7.

10. Wald RM, Juraszek AL, Pigula FA, Geva T. Echocardiographic diagnosis and management of bilateral coronary ostial atresia in a patient with pulmonary atresia and intact ventricular septum. J Am Soc Echocardiogr. 2006;19 e931-3.

11. Eisses MJ, Jimenez N, Permut L, Jones TK, Jonmarker C. Absent aortocoronary connections in a neonate with pulmonary atresia and an intact ventricular septum. J Cardiothorac Vasc Anesth. 2008;22:98-101. 
12. Sarkola T, Boldt T, Happonen JM, Karikoski R, Eronen M. Atresia of proximal coronary arteries in pulmonary atresia with intact ventricular septum-fetal and neonatal findings. Fetal Diagn Ther. 2008;24:413-5.

13. Kipps AK, Powell AJ, Levine JC. Muscular infundibular atresia is associated with coronary ostial atresia in pulmonary atresia with intact ventricular septum. Congenit Heart Dis. 2011;6:444-50.
14. Freeman JE, DeLeon SY, Lai S, Fisher EA, Ow P, Pifarré R. Right ventricle-toaorta conduit in pulmonary atresia with intact ventricular septum and coronary sinusoids. Ann Thorac Surg. 1993;56:1393-5.

15. Laks H, Gates RN, Grant PW, Drant S, Allada V, Harake B. Aortic to right ventricular shunt for pulmonary atresia and intact ventricular septum. Ann Thorac Surg. 1995;59:342-7. 